\title{
Additive Manufacturing - A Growing Possibility to Lighten the Burden of Spare Parts Supply
}

\author{
Steve Rommel and Andreas Fischer \\ Fraunhofer Institute for Manufacturing Engineering and Automation, \\ Nobelstrasse 12, 70569 Stuttgart, Germany \\ \{andreas.fischer, steve.rommel\}@ipa.fraunhofer.de
}

\begin{abstract}
Corporations compete constantly in the market and for market share with their products and services. In order to do so one element is research for new areas of improvement within their products and processes. The focus is often on efficiency and cost effective improvements. The goal is often to provide a superior service or product in comparison to the competition. This is not only true for first time parts but also increasingly important for secondary productsthe spare parts. Spare parts and the spare parts management is becoming a production factor of growing importance. Depending on the type of product or service manufacturers will have to provide spare parts in varying quantities and versions increasing the spare parts management complexity.

For the growing quantity of product types on the market requiring currently enormous warehouses to keep stock for spare parts, with corresponding high costs and complex logistics in combination with continuously decreasing product life time, decreasing time-to-market and increasing regulatory affairs Additive Manufacturing (short: AM) technology could be one solution to lighten the spare parts burden by enabling economically viable, one-off manufacturing on demand and on-location.
\end{abstract}

Keywords: Additive Manufacturing, Spare Parts, Spare Parts Management.

\section{Introduction}

Considering the global but also the local market and the competition of corporations within these markets constant improve of products and processes are required to search and find more cost effective solutions to manufacture products. At the same time services and products need to offer growing possibilities and ways for customers to individualize, specialize and improvise these products. This fact holds also true for spare parts and its market importance.

Today's spare parts industry is characterized by high volume production with sometimes specialized products, long distance transportation and extensive warehousing, resulting in huge inventory of spare parts. These spare parts even hold the risk of being outdated or not usable at the time of need so that they are often scrapped afterwards. On an industrial level, reacting to this burden, companies are competing or collaborating with OEMs, to provide a variety of maintenance services and products which in turn are limited with regards to the broadness and flexibility of their service 
solutions, especially when design or feature changes to spare parts (copies or OEMmanufactured) are required.

Additive Manufacturing offers new sometimes unimaginable possibilities for manufacturing a product which have the potential to change the logistical and business requirements and therefore create the possibilities to lighten the burden. Being a new possibility the following aspects of business need to be further developed with the focus on additive manufacturing:

- standardization of manufacturing processes

- logistics

- product and process management

- certification process

- Product and business management.

The goal of funded and private research projects is to develop a model which incorporates the old and new requirements of manufacturing and the market demands to assist companies to better compete in the market settings.

\section{Addititve Manufacturing and Spare Parts Management}

\subsection{Additive Manufacturing Technologies}

Additive Manufacturing and its technologies involve all technologies used to manufacture a product by adding (placing and bonding) layers of the specific material to each other in a predetermined way. These so called layers are generally speaking 2D-cross-sections of the products 3D-model. AM therefore is creating the geometry as well as the material characteristics during the build predetermined by the material selected. The contour is created in the $\mathrm{x}$-y-direction. The $\mathrm{z}$-direction creates the volume and therefore the 3rd dimension.

Additive Manufacturing offers the possibility to optimize products after each run of parts being build and the lessons learned. There is generally speaking little to no limitations to the freedom in design given by this process. Complex shapes and functional parts can be realized by these innovative processes directly from CAD data. Two examples of technologies are Selective Laser Sintering (SLS) as shown in Figure 1 and Fused Deposition Modeling (FDM) as shown in Figure 2.

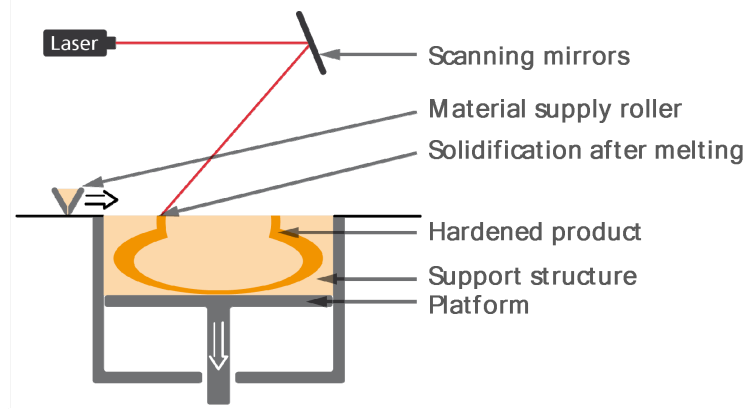

Fig. 1. Schematic diagram of SLS [following VDI 3404] 


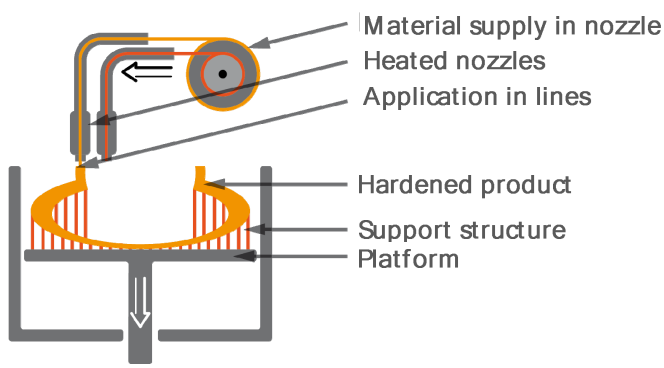

Fig. 2. Schematic diagram of FDM [following VDI 3404]

In order to hold a finished real product in hand two main process steps need to be performed (Gebhardt, 2007):

1. Developing of the cross-sections (layers) of the 3D-model

2. Fabrication of the physical product.

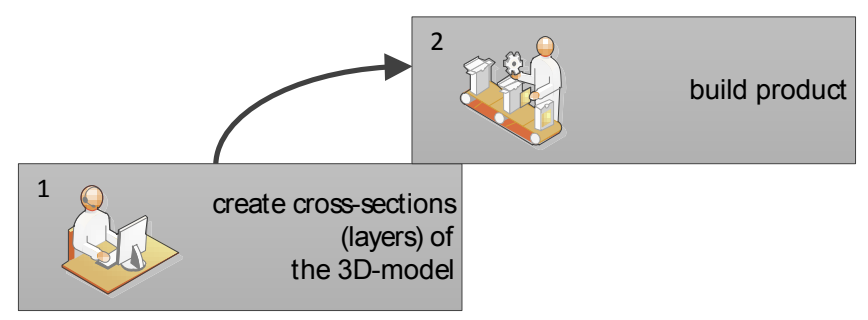

Fig. 3. Figure 3: Two main process steps of AM

These two main process steps either run simultaneously or in sequence depending on the technology. They are broken down into a series of steps following a sequence which is shown in Figure 4 (Gibson et al, 2010):

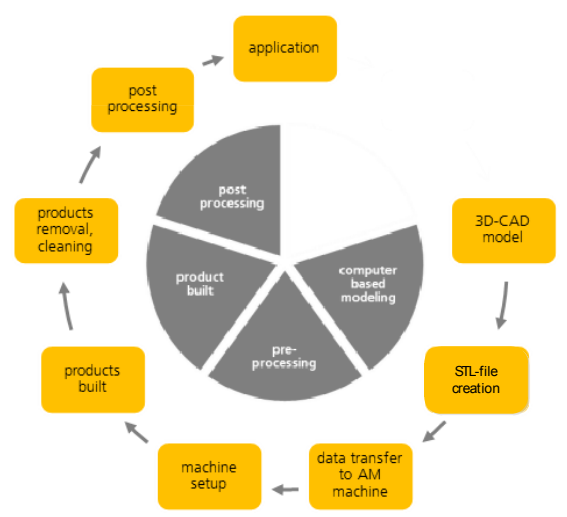

Fig. 4. Process Steps of AM 
In order to withstand the test of being a true addition or even alternative to conventional manufacturing technologies additive manufactured products are looked at possessing the same mechanical and technological characteristics as comparable conventionally manufactured products. This does not equal the fact that its material characteristics have to be exactly the same to the once of conventional technologies. This can be a false point of view and a limiting factor to the use of additive manufacturing, because the new freedom of design offered also offers the possibility to create new products which may look completely different but perform the required function equally well or better.

The thinking has to shift from "get exactly the same product and its material characteristics with another technology, so I can compare it" to "get the same performance and functionality of the product regardless of the manufacturing technology" used.

Besides the benefit of using the 3D-model data directly for the manufacturing process of a product exist additional benefits listed below (Gebhardt, 2007; Hopkinson et. al., 2005):

Table 1. Benefits of Additive Manufacturing

\begin{tabular}{l}
\hline Benefits of AM \\
\hline Integration of functions, increase in complexity of products \\
and components and including of internal structures for the \\
stability of the product \\
\hline Manufacturing of products very difficult or not possible to \\
manufacture with traditional/conventional manufacturing \\
technologies (e.g. undercuts ...) \\
\hline Variation of spare products - ability to adopt "local" require- \\
ments to the same products and therefore supply local mar- \\
kets with the product and its expected features, low effort and \\
no true impact on the manufacturing \\
\hline Customization - two forms of customization are possible - \\
Manufacturer customization (MaCu), and Client customiza- \\
tion (CliCu) \\
\hline No tooling, and reduction in process steps \\
\hline One-piece or small volume series manufacturing is possible, \\
\hline Product-on-demand \\
\hline Alternative logistic strategies based on the current require- \\
ments give the AM an enormous flexibility with regards to the \\
strategy of the business model
\end{tabular}

\subsection{Spare Parts Management}

Spare parts nowadays have become a sales and production factor, especially for any manufacturing company with a highly automated, complex and linked machinery park and production setup. Any production down-time caused by the failure of a component of any equipment within production lines will lead not only to capacity issues but also to monetary losses. These losses may come from (Biedermann, 2008): 
- Distribution: sales lost due to products not being manufactured

- Production: unused material, increase in material usage due to reduced capacity, additional over-time for employees to balance the inventory and make up for the lost production, additional maintenance costs of 2-30\% of overall production costs

- Purchasing and supply chain: increase in storage for spare parts and costs incurred due to the purchase of spare parts

These points alone illustrate the need for each corporation to choose the right spare parts strategy in order to reduce to risk to the business to a minimum by determining the right balance between the minimum inventory and the availability to delivery spare parts intime to prevent production down-time or dissatisfied customers. When choosing this strategy on important aspect is the type of spare parts. According to DIN 13306 a spare part is an "item intended to replace a corresponding item in order to retain or maintain the original required function of the item". Biedermann is defining the items in the following way (Biedermann, 2008):

- Spare part: item, group of items or complete products intended to replace damaged, worn-out or missing items, item groups or products

- Reserve/Back-up item: item, which is allocated to one or more machines (anlagen), and therefore not used individually and in disposition and stored for the purpose of maintenance, Back-up items are usually expensive and are characterized by a low inventory level with a high monetary value

- Consumable item: item, which due to its setup will be consumed during use and has no economically sound way of maintenance

Another aspect in determining the strategy is the type of maintenance the company is choosing or offering. There are three basic strategies:

- Total Preventive Maintenance (TPM): characterized by the performance of inspections, maintenance work and replacement of components prior to the failure of the equipment.

- Scheduled Maintenance or Reliability Centered Maintenance: strategy where the replacement of an item is as the term says planned ahead of time.

- Corrective Maintenance or Repair which is also called Risk Based Maintenance: an item fails and will be replaced in order to convert the installations or equipment back into production mode.

Besides the mentioned type of spare part and the maintenance strategy the following aspects play an equally important role when selecting the strategy

- failure behavior and

- failure rate of the item

- reliability requirements

- level of information available and receivable

- back-up solutions

- Alternatives amongst others.

The decision on the strategy and the type of spare parts determines the logistics and supply chain model to be chosen and therefore the cost for the logistics portion. 


\subsection{Spare Parts Logistics}

The current spare parts logistics strategies are typically focusing on the procurement of spare parts from an already established supplier. In many cases this supplier is responsible for manufacturing the initial primary products. This bares the benefits of an already established business relationship, defined and common understanding of the requirements for the products and services offered, clear definition of the responsibilities, established logistic, established payment modalities and a common understanding of the expectations of either party.

On the other hand there are some downfalls like lack of innovative ideas, unwanted dependence of each other, or an increase in logistics costs to name a few.

The logistics strategy itself is determined by two groups of factors:

1. Exogenous Factors: social and political environment and settings, market situation and competition, type of spare part and customer requirements and expectations [Michalak 2009].

2. Endogenous Factors: company internal factors, in this case inbound, production and outbound logistics.

With the focus on additive manufacturing the parameters for spare parts supplied using Additive Manufacturing are shown in the tables 5-7:

Table 2. Parameter Selection inbound logistics I Rommel, Fraunhofer IPA (following Michalak 2009)

\begin{tabular}{|c|c|c|c|c|}
\hline Paramete & & Paramete & & \\
\hline \multirow{4}{*}{ Sourcing } & $\begin{array}{l}\text { Place of spare } \\
\text { parts production }\end{array}$ & \multicolumn{2}{|c|}{ Internal } & External \\
\hline & $\begin{array}{l}\text { Location of spare } \\
\text { parts manufac- } \\
\text { turer }\end{array}$ & Local & Domestic & Global \\
\hline & $\begin{array}{l}\text { Number of poss- } \\
\text { ible spare parts } \\
\text { manufacturers }\end{array}$ & \multicolumn{2}{|c|}{ Single } & Multiple \\
\hline & $\begin{array}{l}\text { Vertical } \\
\text { production } \\
\text { integration }\end{array}$ & \multicolumn{2}{|c|}{ Components } & Modular \\
\hline \multicolumn{2}{|c|}{ Allocation concepts } & Stock & JIT & Postponement \\
\hline
\end{tabular}

Table 3. Parameter Selection outbound logistics I Rommel, Fraunhofer IPA (following Michalak 2009)

\begin{tabular}{|c|c|c|c|}
\hline \multicolumn{2}{|l|}{ Parameter } & \multicolumn{2}{|l|}{ Parameter Value } \\
\hline \multirow[b]{2}{*}{$\begin{array}{l}\text { Outbound } \\
\text { logistics } \\
\text { structure }\end{array}$} & $\begin{array}{l}\text { Vertical (steps } \\
\text { of distribution) }\end{array}$ & single-step & multiple-step \\
\hline & $\begin{array}{l}\text { Horizontal } \\
\text { (number of } \\
\text { distribution } \\
\text { units) }\end{array}$ & single & multiple \\
\hline \multicolumn{2}{|c|}{ Sales strategy } & \begin{tabular}{l|l|} 
intensive & selective \\
\end{tabular} & exclusive \\
\hline \multicolumn{2}{|c|}{$\begin{array}{l}\text { storage location structure (if } \\
\text { needed) }\end{array}$} & central & local \\
\hline
\end{tabular}


Table 4. Parameter table for selecting the storage location strategy I Rommel, Fraunhofer IPA (following Schulte 2005)

\begin{tabular}{|c|c|c|c|}
\hline \multirow[t]{2}{*}{ Parameter } & \multicolumn{3}{|c|}{ Degree of centralization } \\
\hline & $\begin{array}{l}\text { Trending towards } \\
\text { centralized storage }\end{array}$ & & $\begin{array}{c}\text { Trending towards } \\
\text { decentralized storage }\end{array}$ \\
\hline Assortment & broad & e..... & limited \\
\hline Delivery time & sufficient & 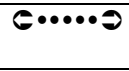 & $\begin{array}{c}\text { fastest delivery (specific } \\
\text { time ...) }\end{array}$ \\
\hline Product value & high & e..... & low \\
\hline $\begin{array}{l}\text { Level of concentration } \\
\text { of manufacturing sites }\end{array}$ & one source & 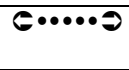 & multiple sources \\
\hline Customer structure & $\begin{array}{l}\text { few big size } \\
\text { companies }\end{array}$ & 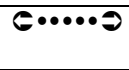 & $\begin{array}{c}\text { many small sized } \\
\text { companies }\end{array}$ \\
\hline $\begin{array}{l}\text { Specific storage } \\
\text { requirements }\end{array}$ & yes & 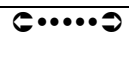 & no \\
\hline $\begin{array}{l}\text { Specific } \\
\text { national/regional } \\
\text { requirements }\end{array}$ & few & e....? & many \\
\hline
\end{tabular}

\section{New Process Design and Business Model}

\subsection{Proposed Process Flow}

Derived from the limitations and effects of the current supply strategies of spare parts, customer feedback from questionnaires and based on the processes of AM in combination with the product figure 5 illustrates a generic conventional process flow model and figure 6 the proposed preliminary process flow model.

As with standard process models the proposed process flow model covers all the process steps starting with the input from the market in the form of customer orders and customer feedback up until the delivery of the finished product to the customer.

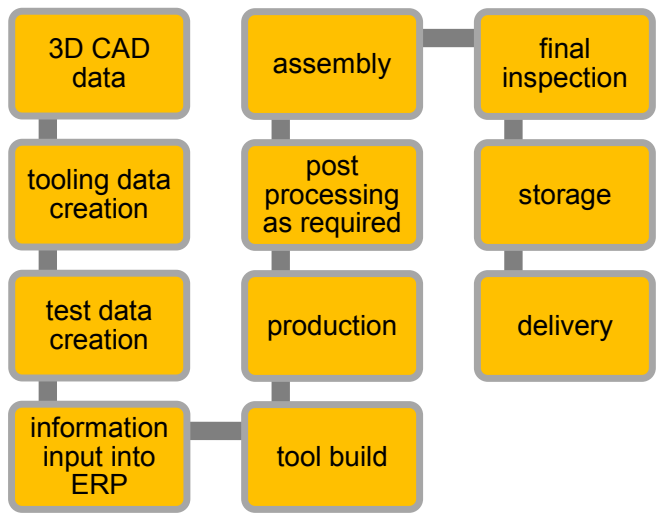

Fig. 5. Conventional process flow

The process model will be in a permanent updating stage for some time due to the development stage of the technologies.

Producing parts using Additive Manufacturing technologies has an impact on multiple levels and multiple areas of a business' operation. 


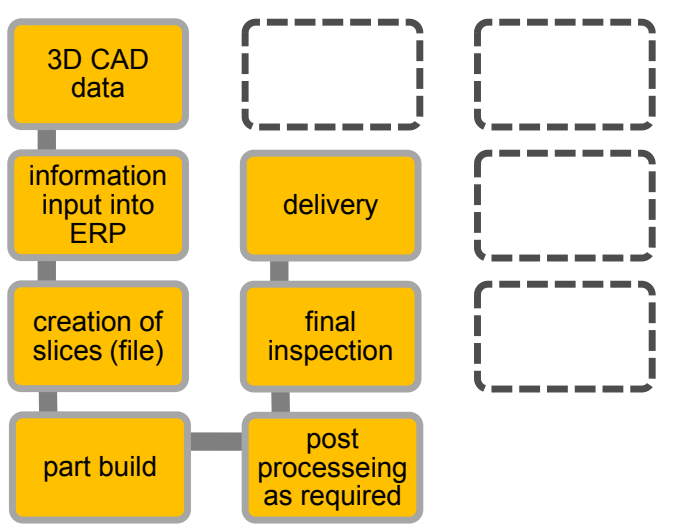

Fig. 6. Preliminary Process Model

\subsection{Impact of AM Technologies on Spare Parts Manufacturing}

The impact of using AM technologies to manufacture spare parts will be described in the following subchapter. This chapter presents only an overview of the main benefits.

\subsubsection{Reduction or Elimination of Tooling}

Conventional manufacturing like injection molding requires various tools in order to fabricate a product from start to finish. This results not only in costs for the tool build and tooling material, but also in time for the tool build, setup procedures during production periods and maintenance activities in order to keep the tools and therefore production running. Additionally tooling often has to be stored for a defined time after the end of production (EOP) to be able to produce spare parts when needed.

There are two possible alternatives to the conventional way of manufacturing spare parts being proposed: one being the fabrication of products including its spare parts strictly using Additive Manufacturing technologies from the start, thus eliminating tooling completely. The other alternative is to manufacture primary products using conventional technologies including tooling but manufacturing spare parts using Additive Manufacturing technologies.

In order to make a decision which alternative is to be preferred the suggestion is to perform an analysis of the spare part in question to determine the potentials and risks of using Additive Manufacturing. Depending on the spare parts characteristics and the spare parts strategy the following benefits can be achieved:

- Reduction or elimination of tooling

- Freeing up storage space for not needed tooling

- Freeing up storage space for already produced products

- Reduction in costs for logistics

- Freeing up production time for not required products to be made ahead of time after EOP

- Reductions of obsolete or excessive spare parts being produced at EOP and being disposed if not required. 
In the case of spare parts an additional benefit is that product failures causing the need for spare parts can be examined and corrective actions can be implemented into the product design without the need to also change or update tooling data, tooling and processes.

\subsubsection{Reducing Complexity}

The manufacturing of spare parts directly from 3D CAD data significantly reduces the complexity in organizational and operational processes e.g. reduction of data transfers and conversion for the various tools and equipment.

On the other hand, handling of data is much more convenient than handling of real parts, but also required a secured loop in order to assure the correct data handling and storage. Within the mega trend of customization / individualization of products it is very easy to produce lots of different versions and personalized products with very little additional effort short-term and long-term. Data handling of all the versions will be the limitation.

\subsubsection{Manufacturing "On Demand" and "On Location"}

The main advantage of Additive Manufacturing spare parts is the possibility to produce these parts on demand. Two alternative models of this process are possible. First the spare parts will be kept on stock in very small numbers and the customer demand will trigger the delivery of the parts from the stock and the immediate production of the desired number of parts to refill the stock. Second is to eliminate the stock and produce directly the number and version of parts that the customer demands. The timing demand will be longer but no capital will be tied up in the spare parts sitting in storage. Another advantage is the future production on location: Production on location envisions sending the 3DCAD part data with additional information regarding building process, materials and tolerances to a production site close to the customer. The parts could be manufactured in independent or dependent production facilities that have clearly defined and certified Additive Manufacturing capacities. This model could have a large impact on the logistics that will be evaluated. The impact of a production on demand, on location and with local material is recapped in the following table 5:

Table 5. Impact of Additive Manufacturing on Spare Parts

\begin{tabular}{lll}
\hline On demand & On location & Local material \\
\hline $\begin{array}{l}\text { No more warehousing for } \\
\text { spare parts including space, } \\
\text { building maintenance, ener- } \\
\text { gy for climate control, } \\
\text { workers... }\end{array}$ & $\begin{array}{l}\text { Worldwide service } \\
\text { without limitations }\end{array}$ & $\begin{array}{l}\text { Reaction on local re- } \\
\text { quirements }\end{array}$ \\
\hline $\begin{array}{l}\text { No more logistics of scrap- } \\
\text { ping unused old spare parts }\end{array}$ & $\begin{array}{l}\text { No more logistics for } \\
\text { end products }\end{array}$ & Environmental friendly \\
\hline $\begin{array}{l}\text { No more time limitations } \\
\text { for spare parts support }\end{array}$ & $\begin{array}{l}\text { Faster response time } \\
\text { over long distances }\end{array}$ & $\begin{array}{l}\text { Much less raw material } \\
\text { logistics }\end{array}$ \\
\hline & & $\begin{array}{l}\text { Social benefits of job } \\
\text { creation in the local area }\end{array}$ \\
\hline & & Cultural adaption \\
\hline
\end{tabular}




\subsubsection{Business Model Opportunities}

Staying competitive using traditional business model concepts is becoming more and more difficult. Customization and the response time to customer needs are two critical factors of being successful. 21st century companies have to focus on moving physical products as well as their information quickly through retail, distribution, assembly, manufacture and supply. This is part of the value proposition manufacturing and service providers offer to their customers. Using Additive Manufacturing can provide a significant competitive advantage to a company.

Business models which consist of a deeper cooperation between suppliers and receivers of on-demand parts with possible virtual networks will have to be developed. The stake holders involved vary depending on the type of spare part and the setup between the manufacturer and the user. The involved stake holders are shown in figure 7.

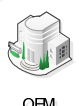

Овм

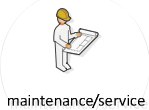

provider

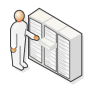

DW

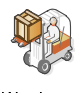

Warehouse

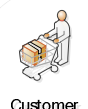

Customer

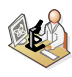

ESP

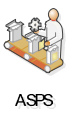

Fig. 7. Key stake holders of an Additive Manufactured Spare Parts logistics

The involvement of these stake holders can vary as shown in figure 8:

Considering the different possible scenarios of the involvement of the key stake holders one examples of the setup of such business models is illustrated in figure 9: 


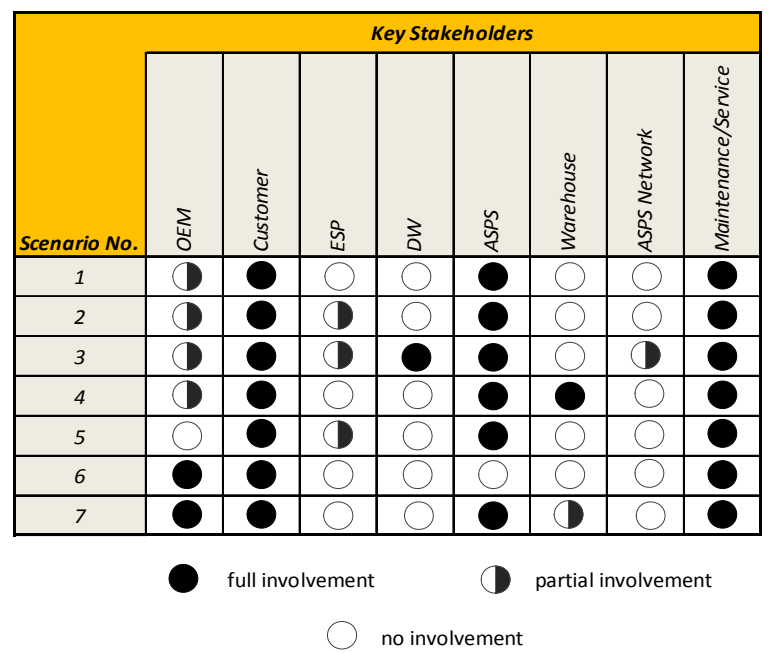

Fig. 8. Involvement of key stake holders

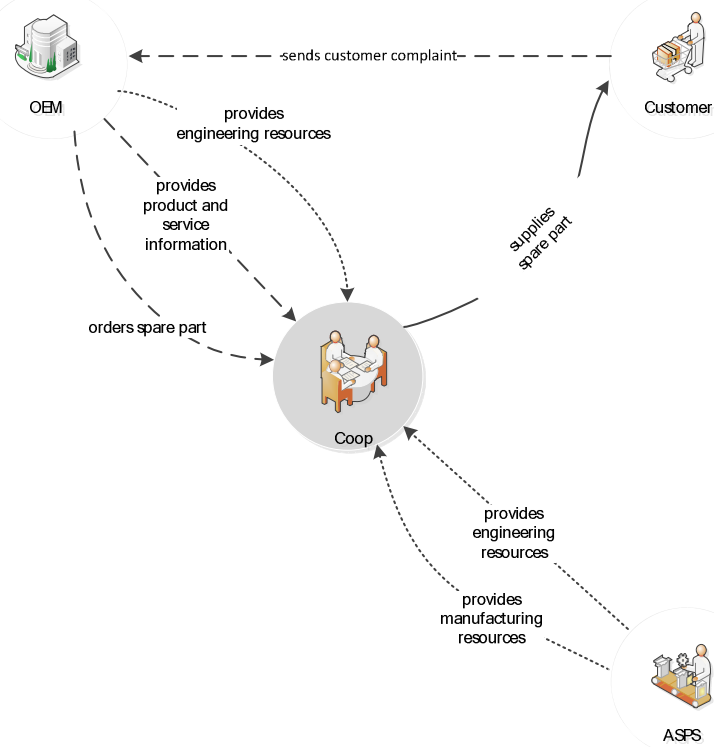

Fig. 9. Additive Manufacturing Coop

Depending on the business model each player has a different level of involvement and therefore a different level of value creation he adds to the overall product. 


\section{Conclusions and Outlook}

Implementing and using Additive Manufacturing in order to manufacture spare parts offers a viable option not only to familiarize one with a new emerging manufacturing technology but also presents opportunities to offer products and services to the customer which fit their desire and requirements regarding time and cost effective deliver.

It is however important to take in account that Additive Manufacturing has also its current limitations like size, surface finish quality and the production volume (number of parts). Additive Manufacturing and its benefits has the potential of an enormous economic impact by reducing inventory levels to an absolute minimum as well as reducing logistics cost significantly.

\section{References}

1. Becker, R.: Midterm Report - Direct Spare. Fraunhofer IPA, Stuttgart (2010)

2. Biedermann, H.: Ersatzteilmanagement: Effiziente Ersatzteillogistik für Industrieunternehmen (VDI-Buch). Springer, Heidelberg (2008)

3. Gebhardt, A.: Generative Fertigungsverfahren: Rapid Prototyping - Rapid Tooling - Rapid Manufacturing. Carl Hanser Verlag GmbH \& CO. KG, München (2007)

4. Gibson, I., Rosen, D.W., Stucker, B.: Additive Manufacturing Technologies: Rapid Prototyping to Direct Digital Manufacturing. Springer, New York (2009)

5. Hopkinson, N., Hague, R., Dickens, P.: Rapid Manufacturing: An Industrial Revolution for the Digital Age: The Next Industrial Revolution. John Wiley \& Sons, West Sussex (2005)

6. Pfohl, H.: Logistiksysteme - Betriebswirtschaftliche Grundlagen. Springer, Heidelberg (2010)

7. Wirtz, B.: Business Model Management: Design - Instruments - Success Factors. Gabler Verlag, Heidelberg (2011)

8. Rommel, S., Becker, R.: Supplying Spare Parts using AM Technologies. In: Proceedings of the 1st Annual International Conference on Industrial Engineering Theory, Applications and Practice, Stuttgart, Germany 